\title{
ANÁLISE DE VELOCIDADES DE DADOS SÍSMICOS MULTICOMPONENTE DA BACIA DE SANTOS UTILIZANDO TECNOLOGIA OBN E TÉCNICA SWD
}

\author{
N. R. C. F. ZUNIGA* \\ Instituto de Astronomia, Geofísica e Ciências Atmosféricas - Universidade de São Paulo \\ nelson.zuniga@iag.usp.br
}

Submetido 03/10/2016 - Aceito 21/02/2018

DOI: $10.15628 /$ holos.2018.5127

\section{RESUMO}

A sísmica multicomponente apresenta um campo de onda bem mais completo do que a sísmica convencional, em decorrência disso ela vem sendo cada vez mais utilizada nos levantamentos sísmicos. Junto à ela, a tecnologia OBN (Ocean Bottom Nodes) é necessária em aquisições marítimas para a obtenção de ondas convertidas. Com o aumento da profundidade dos reservatórios encontrados, existe cada vez mais dificuldade com relação à qualidade dos dados de amplitude obtidos, dessa forma aquisições sísmicas durante a perfuração diminuiriam este problema. Entretanto esse conjunto de técnicas e tecnologias torna o evento sísmico de reflexão muito mais complexo, o que dificulta significativamente a análise de velocidades. Com isso, é necessário utilizar métodos de otimização e
\end{abstract}

análise de velocidades que sejam capazes de controlar as características não-hiperbólicas de um evento de reflexão. Para isso, será utilizada uma equação nãohiperbólica multiparametrica buscando efetuar a análise de velocidades por meio do ajuste entre a curva de tempos de trânsito calculada e observada, tratando como um problema de inversão segundo um critério de otimização. Dessa forma, foi possível observar que uma equação não-hiperbólica multiparametrica supriu as dificuldades oriundas dos fatores que geram a nãohiperbolicidade nos eventos de reflexão. Mesmo com a qualidade do ajuste dos dados tendo diminuindo com o aumento da profundidade, a utilização da sísmica multicomponente apresentou resultados eficientes quando usada durante a perfuração.

PALAVRAS-CHAVE: Sísmica multicomponente, OBN, SWD.

\section{VELOCITY ANALYSIS OF MULTICOMPONENT SEISMIC DATA OF THE SANTOS BASIN USING OBN TECHNOLOGY AND SWD TECHNIQUE}

\begin{abstract}
The multicomponent seismic presents a more complex wave field than the conventional seismic, for this reason it has been used in seismic survey. For the offshore situations, there is the necessity of use OBN (Ocean Bottom Nodes) technology to obtain converted wave informations. With the increase of the depth of the reservoirs found, there is more difficulty concerning the quality of the amplitude data obtained. Therefore, the seismic survey during the drilling operation would reduce this problem. However, this set of techniques and technologies cause a more complex reflection seismic event, what difficult the velocity analysis. In this situation it must be used an optimization method and velocity analysis which are capable of control the
\end{abstract}

nonhyperbolic characteristics. For this reason, it will be used a nonhyperbolic multiparametric travel-time approximation aiming to perform the velocity analysis by the curve fitting between the observed and calculated curve, and treating it as an inverse problem by an optimization criterion. Thus, it was observed that a nonhyperbolic multiparametric equation was able to supply the difficulties from the factors which generate the nonhyperbolicity in the reflection events. Even with a enhance in the quality of the data fitting decreasing with the depth, the using of the multicomponent seismic shown efficient results when it was used joint to the drilling operation.

KEYWORDS: Multicomponent seismic, OBN, SWD. 


\section{INTRODUÇÃO}

A sísmica multicomponente vem sendo utilizada cada vez mais em decorrência das grandes melhorias que ela gera na qualidade das informações obtidas em um levantamento sísmico marítimo (STEWART, GAISER, BROWN e LAWRON, 2002; 2003). Entretanto, a necessidade de obtenção de ondas $S$ leva ao uso da tecnologia OBN (Ocean Bottom Nodes). As características de conversão de onda originadas da sísmica multicomponente juntamente com o uso da tecnologia OBN (que impõe uma diferença de profundidade entre fonte e receptor) gera um evento não-hiperbólico muito mais intenso, o que dificulta uma importante etapa do processamento sísmico, a análise de velocidades. Por tal motivo, existe a necessidade de utilizarse de técnicas que sejam capazes de controlar essa não-hiperbolicidade.

Algo que vem ganhando popularidade é a técnica SWD (Seismic While Drilling), a qual se é descida, junto das demais ferramentas, uma fonte sísmica que permite aquisições ao longo da perfuração (PETRONIO e POLETTO, 2002; ALEOTTI et al., 2011). Isso ajuda a solucionar alguns problemas de obtenção de dados com baixa amplitude em decorrência das aquisições muito profundas (MIRANDA et al., 1996; DETHLOFF, CORNISH e DEADY, 2007). Entretanto, como a fonte fica em uma profundidade maior do que a dos receptores retorna-se a um cenário similar ao da tecnologia OBN (receptores mais profundos do que a fonte), onde temos uma assimetria no raio sísmico tornando o evento ainda mais não-hiperbólico.

Dessa forma é necessário avaliar se é aplicável a combinação da sísmica multicomponente e tecnologia OBN junto da técnica SWD para efetuar a análise de velocidades.

O modelo trabalhado trata-se de um reservatório de carbonato do pré-sal da Bacia de Santos selado por uma estrutura salina de 2411 metros de espessura (Figura 1).
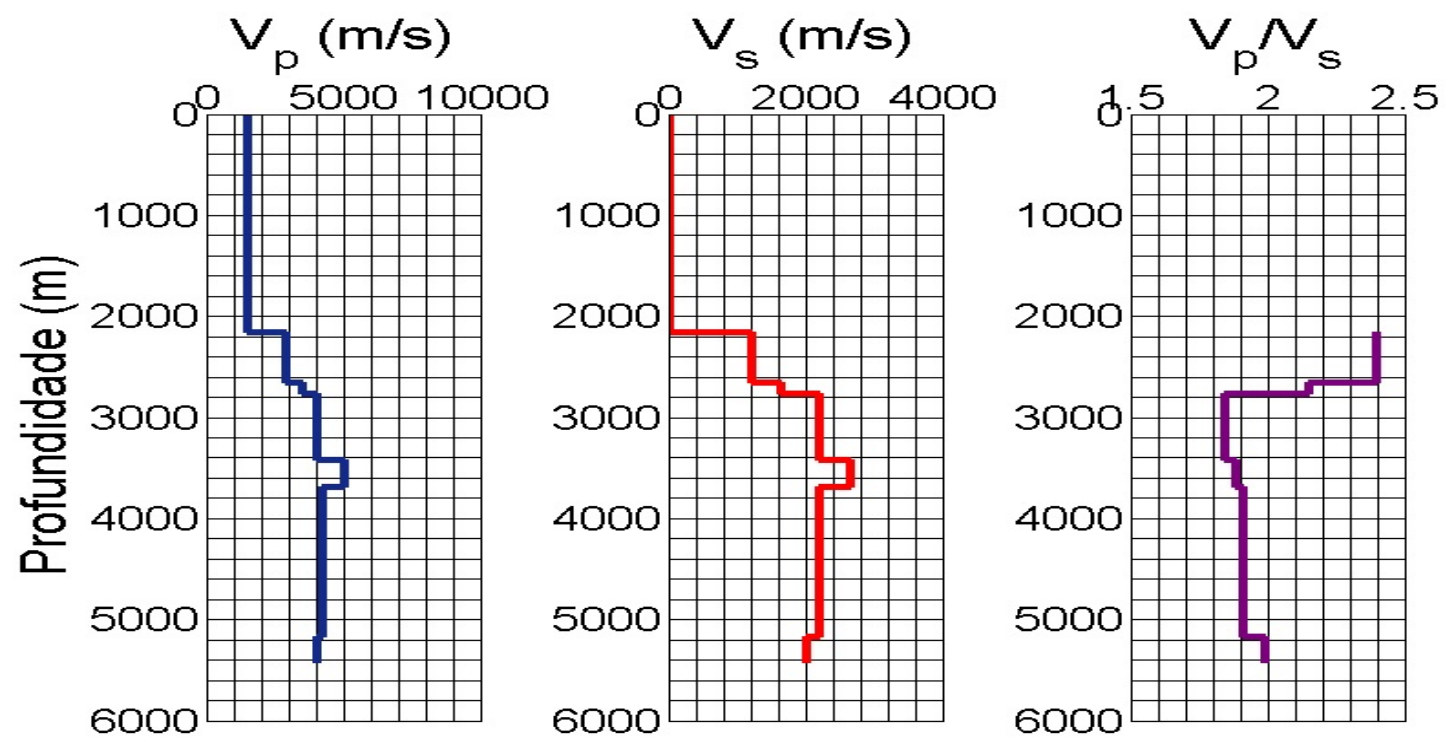

Figura 1: Perfil de velocidades de onda $P$, onda $S$ e razão $V p / V s$ do modelo em função da profundidade. 


\section{METODOLOGIA}

Inicialmente é necessário compreender a complexidade do modelo trabalhado. Para tal, deve ser estudada a topografia da função objetivo utilizada e relacionada ao modelo, e dessa forma é possível definir o quão complexa é a função, para identificar o tipo de método de otimização a ser utilizado. Dessa forma podem-se extrair os parâmetros necessários e efetuar a análise de velocidades.

A aproximação utilizada trata-se da equação de Li e Yuan (2001), Equação (1), que utiliza $\gamma$ como parâmetro de não-hiperbolicidade, Equação (2), para que seja possível obter melhores informações e controlar os efeitos de conversão de onda, longos afastamentos e anisotropia. 0 vetor $x$ é a representação de cada afastamento representando cada receptor em que são captadas as informações das ondas sísmicas, $t_{0}$ é o tempo de propagação para um afastamento nulo, quando a onda se propaga pela componente perpendicular ao plano em que ela sofreu reflexão, e $v$ é a velocidade média quadrática da onda sísmica refletida. Dessa maneira, para cada receptor, representados pelo vetor $x$, há um valor de $t$, resultando em uma curva não-hiperbólica de tempos de trânsito registrada pelo conjunto receptores.

$$
\begin{aligned}
& t=\sqrt{t_{0}^{2}+\frac{x^{2}}{v^{2}}-\frac{(\gamma-1)}{\nu^{2}} \frac{(\gamma-1) x^{4}}{4 t_{0}^{2} v^{2}+(\gamma-1) x^{2}}} \\
& \gamma=\frac{v_{p 2}^{2}}{v_{C 2}^{2}}=\frac{\gamma_{e f f}\left(1+\gamma_{0}\right)}{\left(1+\gamma_{e f f}\right)}
\end{aligned}
$$

Onde $\gamma$ é a razão entre a velocidade de empilhamento de onda $\mathrm{P}$ ao quadrado e a velocidade de empilhamento de onda convertida ao quadrado, $V_{P 2}$ é a velocidade de empilhamento de onda $P, v_{C 2}$ é a velocidade de empilhamento de onda convertida, $\gamma_{2}$ é a razão entre as velocidades de empilhamento de ondas $P$ e $S$, e $\gamma_{0}$ é a razão entre as velocidades das ondas $\mathrm{P}$ e $\mathrm{S}$ que se propagam através da componente normal.

$O \gamma_{\text {eff }}$ é a razão entre $\gamma_{2}$ ao quadrado e $\gamma_{0}$, Equação (3).

$$
\gamma_{e f f}=\frac{\gamma_{2}^{2}}{\gamma_{0}}
$$

Tendo a curva de tempos de trânsito registrada pelos receptores, deve-se ajustar a curva calculada utilizando a equação Li e Yuan (2001) com a curva observada no registro, para que dessa maneira seja possível identificar os valores necessários dos parâmetros para efetuar o ajuste com o menor erro possível, permitindo uma melhor caracterização estrutural do modelo estudado.

Como a aproximação utilizada possui três parâmetros incógnitas, deve-se seguir uma rotina de inversão segundo um critério de otimização. Com isso será utilizado o método dos 
mínimos quadrados como método de minimização de erro entre as curvas, e o algoritmo de Nelder e Mead (1965) como algoritmo de otimização para encontrar o menor valor de mínimo, que está associado aos valores dos parâmetros que melhor caracterizam a realidade do modelo (mínimo global). Como a equação utilizada é multimodal (apresenta valores de mínimo global e mínimos locais) deve-se utilizar um procedimento de globalização do algoritmo de otimização, para não correr o risco de alcançar apenas um dos mínimos locais durante a inversão. Nesse tipo de procedimento de globalização do algoritmo são efetuadas diversas inversões nas quais o algoritmo de otimização efetua o ajuste diversas vezes, para que seja possível identificar o menor valor de mínimo e ter certeza de que está relacionado ao valor de mínimo global.

Sendo ajustada a curva calculada com a observada, será possível inferir a qualidade do ajuste em cada um dos conjuntos de aquisição. Com essas informações será possível definir se é possível efetuar o ajuste de curvas de tempos de trânsito não-hiperbólicos utilizando a técnica SWD.

\section{RESULTADOS E DISCUSSÃO}

Inicialmente foi possível observar que existe uma significativa complexidade na topografia da função objetivo (Figura 2), demonstrando ser uma equação multimodal, que apresenta uma região de mínimo global, associado aos parâmetros que são a melhor solução para a função, como também apresenta uma região de mínimo local, associado ao conjunto de parâmetros que também são uma solução da função, porém não a melhor solução possível. Isso traz a necessidade de se utilizar múltiplas inversões para que seja possível obter uma distribuição de informações confiável e não exista o risco de atingir-se apenas um dos mínimos locais.

Os eventos de reflexão de onda PP (Figuras 3 e 4) apresentaram, em cada conjunto de dados, tempos de trânsito residuais muito baixos, da ordem de $10^{-4}$ e $10^{-3}$. Isso mostra uma boa qualidade do ajuste obtido entre a curva de tempos de trânsito calculada e a registrada pelos receptores. No caso dos eventos de reflexão de onda convertida PS, também foram observados bons ajustes até a aquisição de 3687 metros (Figuras 5 e 6), da ordem de $10^{-3}$. Uma maior dificuldade no ajuste foi observada com relação aos dados de tempos de trânsito da última aquisição de evento de onda convertida, o que já era esperado devido à crescente assimetria entre os raios sísmicos, entretanto esses valores de residual ainda são muito baixos.

Diferentemente de trabalhos anteriores (MIRANDA et al., 1996; PETRONIO e POLETTO, 2002; DETHLOFF, CORNISH e DEADY, 2007; ALEOTTI et al., 2011), que visam obtenção de informações de ondas $\mathrm{P}$ e ondas $\mathrm{S}$ próximas ao poço perfurado, o presente trabalho apresentou a possibilidade de obter informações que contribuam para uma melhor caracterização geológica e estrutural do reservatório de maneira mais ampla. 


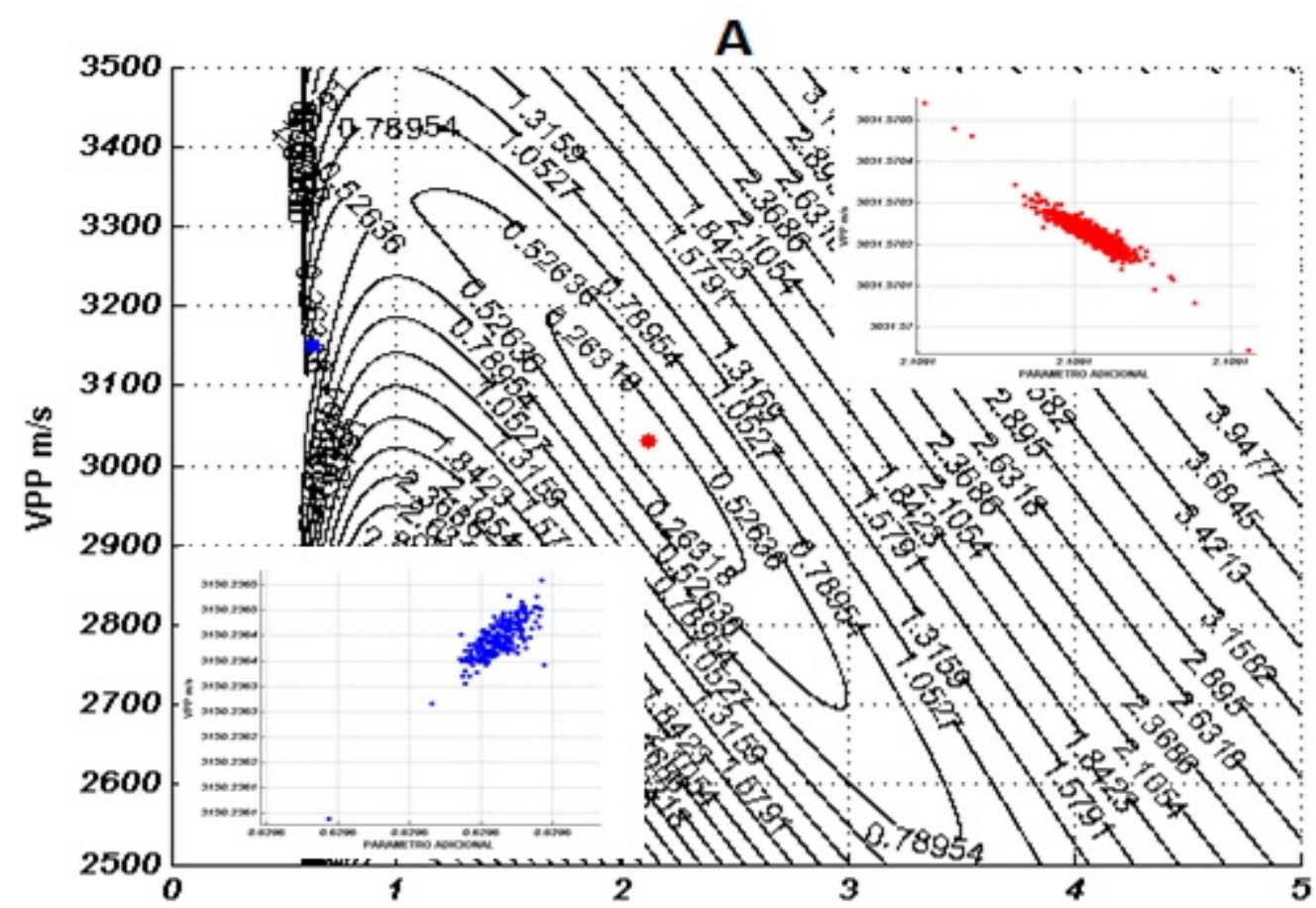

B

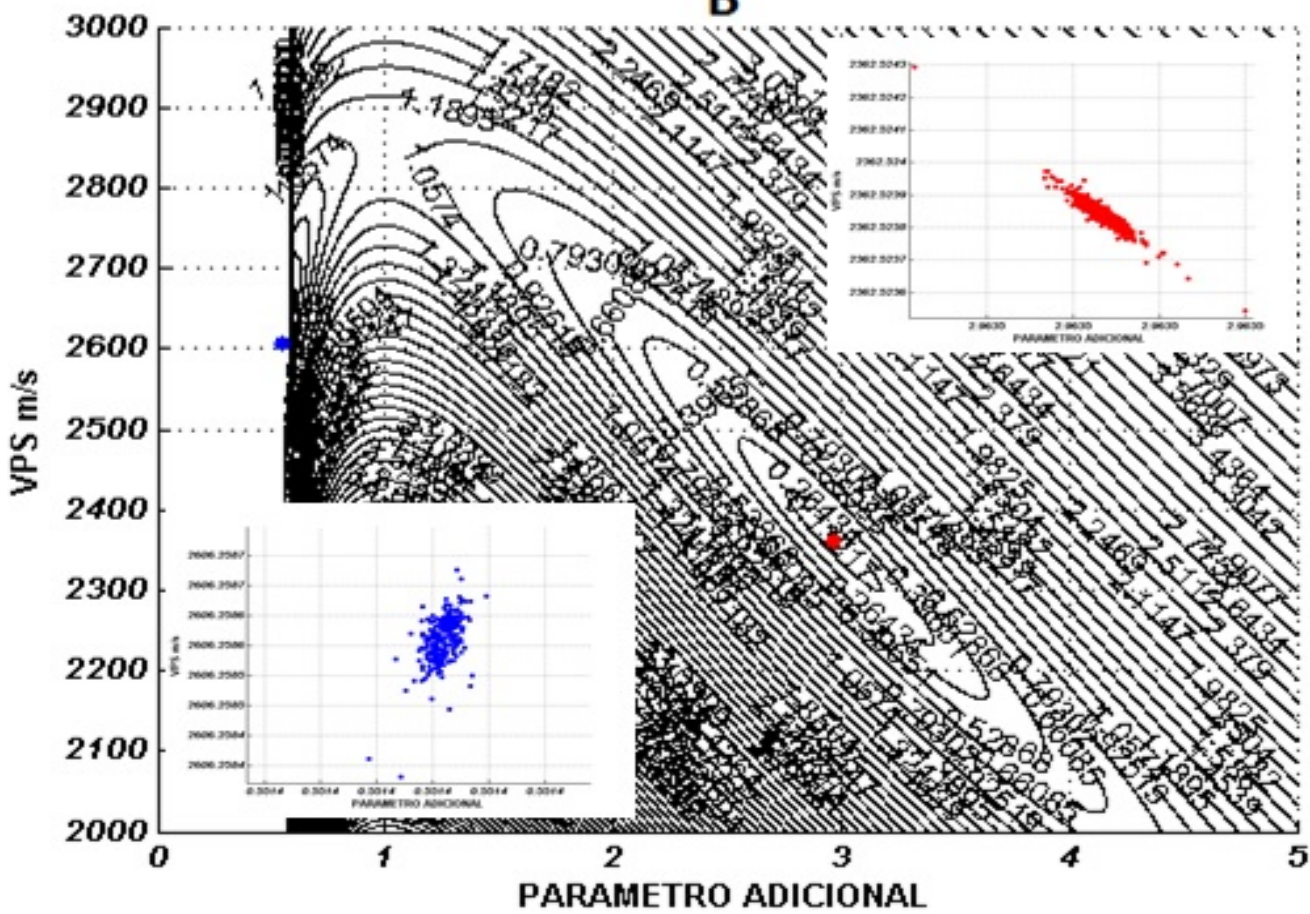

Figura 2: Mapas de dispersão sobrepostos ao mapa residual da função objetivo mostrando a complexidade da aproximação não-hiperbólica multiparamétrica proposta por Li e Yuan (2001) para (A) o evento de reflexão de onda PP e para (B) o evento de reflexão de onda convertida PS. As dispersões em vermelho representam a região de mínimo global da função e as dispersões em azul representam as regiões de mínimos locais da função. 

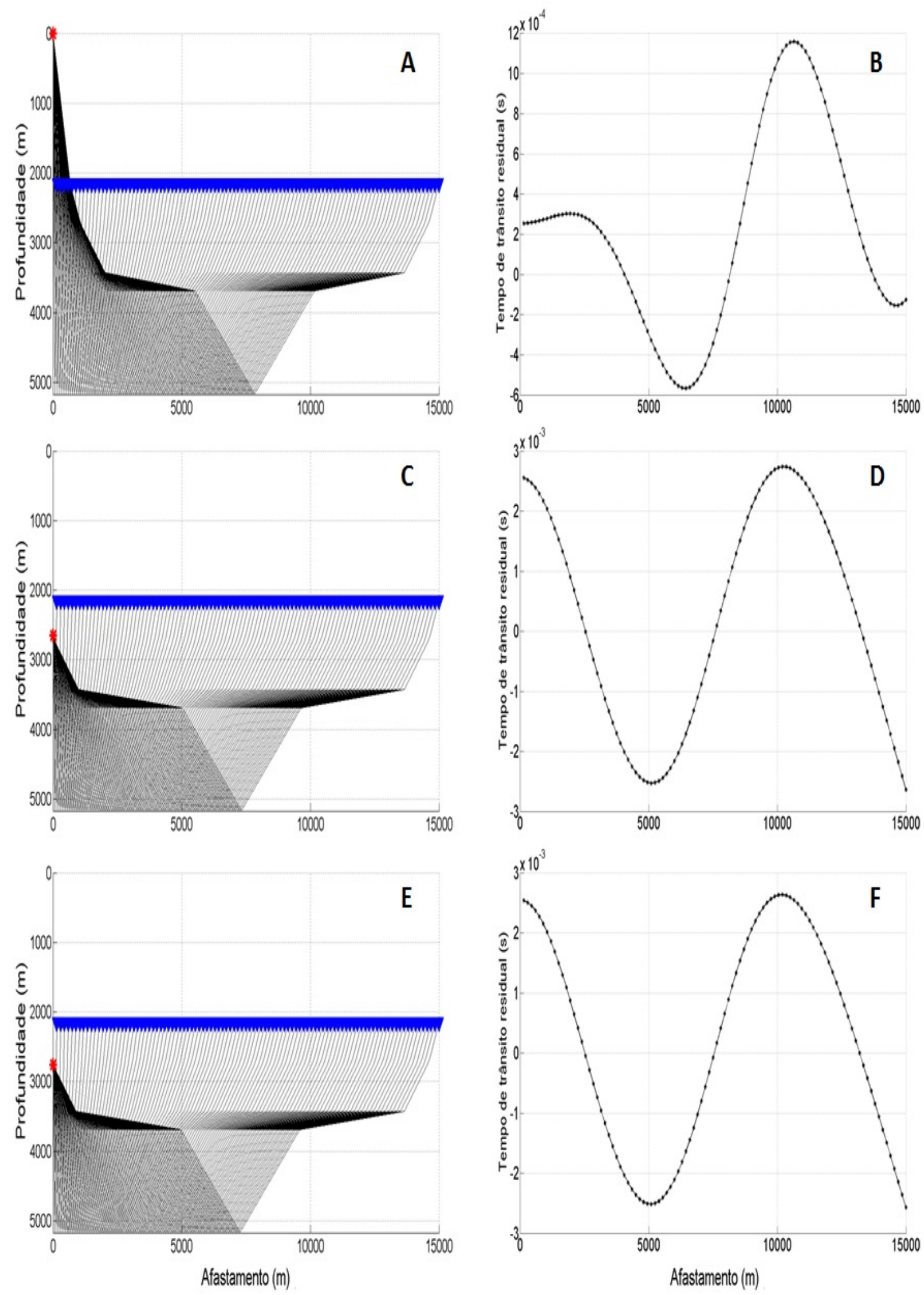

Figura 3: Esquematização de traçado de raios e residual de tempos de trânsito de evento de reflexão de onda PP (A e B) para aquisição feita com canhão de ar próximo da superfície marinha, (C e D) para aquisição feita com SWD na profundidade de 2653 metros, e (E e F) para aquisição feita com SWD na profundidade de 2761 metros. 

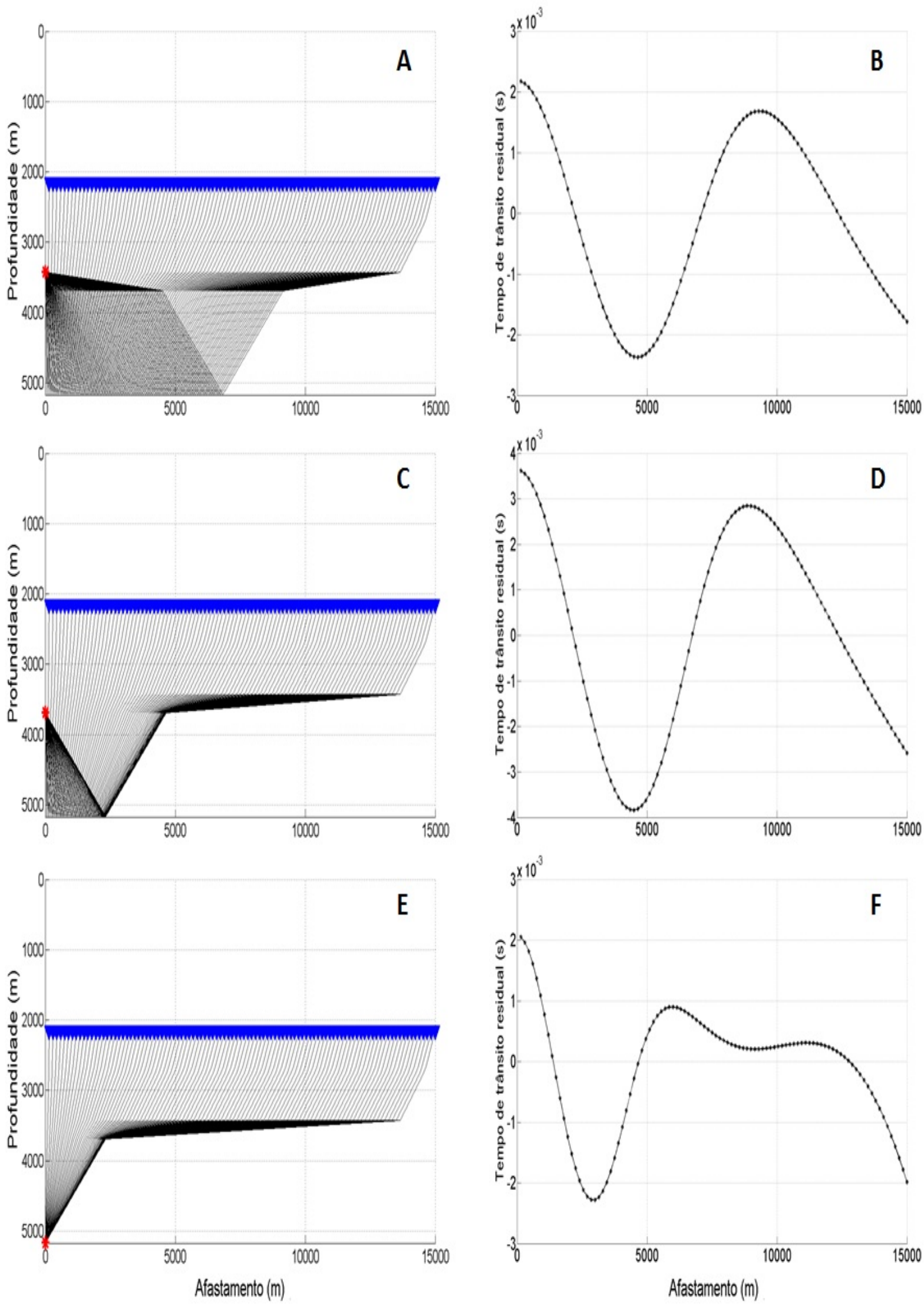

$3^{\times 10^{3}}$

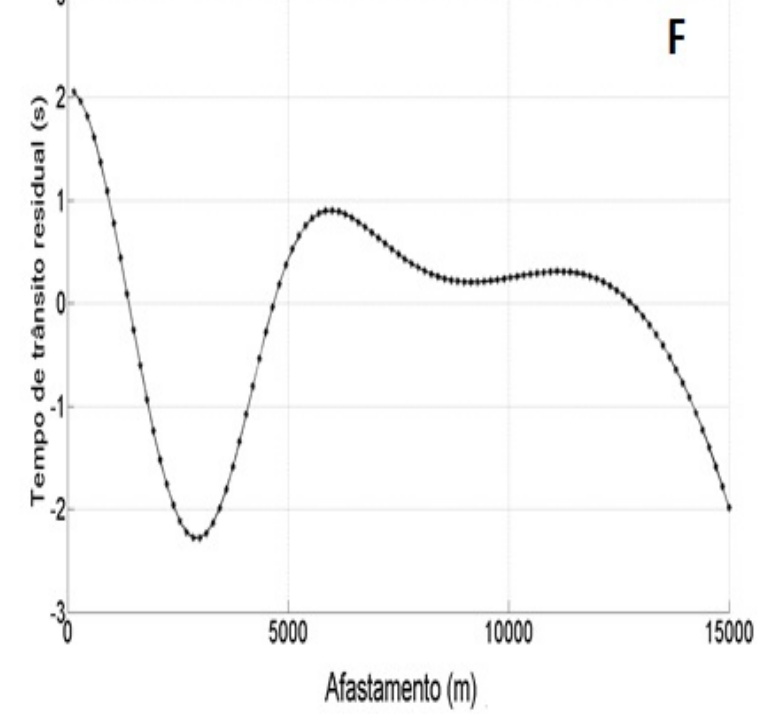

Figura 4: Esquematização de traçado de raios e residual de tempos de trânsito de evento de reflexão de onda PP (A e B) para aquisição feita com SWD na profundidade de 3425 metros, (C e D) para aquisição feita com SWD na profundidade de 3687 metros, e (E e F) para aquisição feita com SWD na profundidade de 5172 metros. 

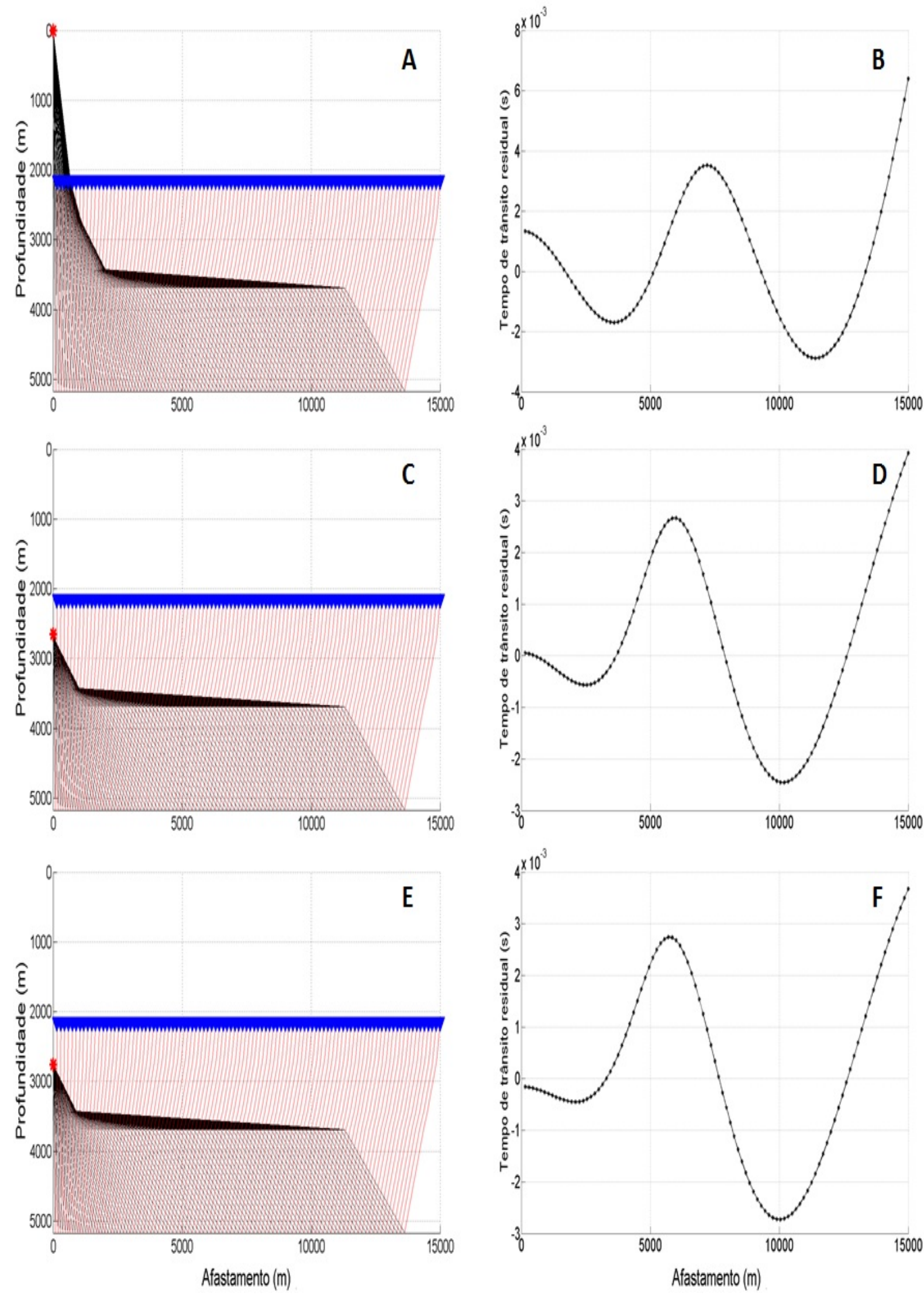

Figura 5: Esquematização de traçado de raios e residual de tempos de trânsito de evento de reflexão de onda convertida PS (A e B) para aquisição feita com canhão de ar próximo da superfície marinha, (C e D) para aquisição feita com SWD na profundidade de 2653 metros, e (E e F) para aquisição feita com SWD na profundidade de 2761 metros. 

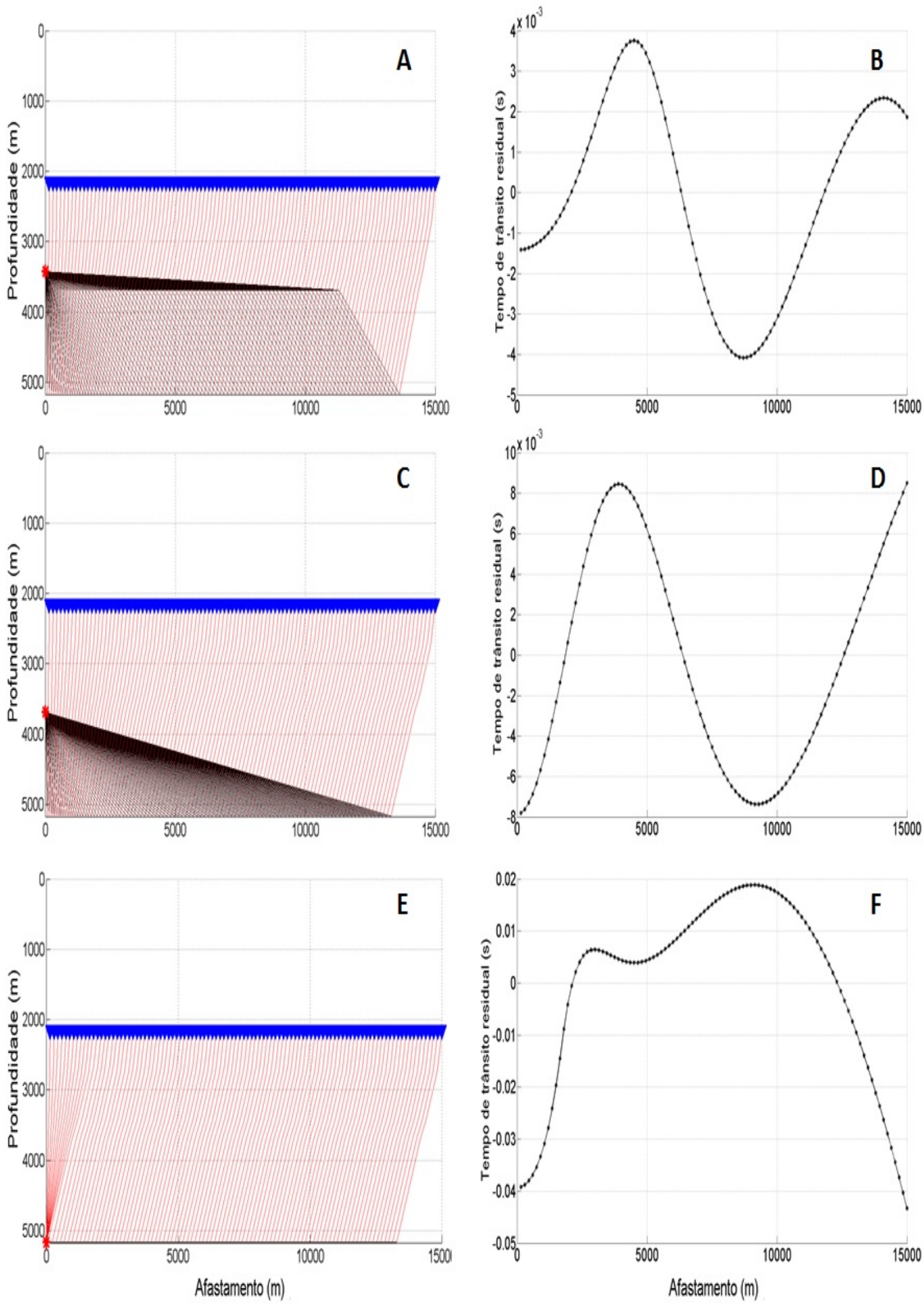

Figura 6: Esquematização de traçado de raios e residual de tempos de trânsito de evento de reflexão de onda PP (A e B) para aquisição feita com SWD na profundidade de 3425 metros, (C e D) para aquisição feita com SWD na profundidade de 3687 metros, e (E e F) para aquisição feita com SWD na profundidade de 5172 metros. 


\section{CONCLUSÕES}

Foi possível identificar que a necessidade do uso de uma equação complexa é de suma importância, pois com a diferença de profundidade entre fonte e receptores traz muitas complicações para a análise de velocidades, além das demais características que já tornam o evento de reflexão não-hiperbólico. A rotina de inversão juntamente com o método de otimização utilizado apresentaram ótimos resultados. Com os residuais de tempos de trânsito muito pequenos, foi possível observar que o método proposto no presente trabalho é aplicável e muito útil se trabalhado com a técnica SWD, possibilitando uma melhor caracterização estrutural do reservatório estudado.

\section{REFERÊNCIAS}

Aleotti, L., Poletto, F., Miranda, F., Corubolo, P., Abramo, F., Craglietto, A. (2011). Seismic whiledrilling technology: use and analysis of the drill-bit seismic source in a cross-hole survey. Geophysical Prospecting, (47), 25-39.

Dethloff, M. H., Cornish, B., Deady, R. (2007). Seismic While Drilling. $69^{\text {th }}$ EAGE Conference and Exhibition incorporating SPE EUROPEC.

Li, X. Y., Yuan, J. (2001). Converted-wave moveout analysis revised: The search for a standard approach. $73^{\text {rd }}$ Annual International Mtg. Soc. Expl. Geophysics.

Miranda, F., Aleotti, L., Abramo, F., Poletto, F., Craglietto, A., Persoglia, S., Rocca, F. (1996). Impact of the seismic 'While Drilling' technique on exploration wells. First Break, (14), 55-68.

Nelder, J. A., Mead, R. (1965). A simplex method for function minimization. The Computer Journal, (7), 308-313.

Petronio, L., Poletto, F. (2002). Seismic-while-drilling by using tunnel boring machine noise. Geophysics, (67), 1798-1809.

Stewart, R. R., Gaiser, J. E., Brown, R. J., Lawron, D. C. (2002). Converted-wave seismic exploration: Methods. Geophysics, (67), 1348-1363.

Stewart, R. R., Gaiser, J. E., Brown, R. J., Lawron, D. C. (2003). Converted-wave seismic exploration: Applications. Geophysics, (68), 40-57. 